\title{
Cultivating Systemic Thinking in the Next Generation of Business Leaders
}

\author{
J. BRIANN ATWATER \\ VIJAY R. KANNAN \\ ALAN A. STEPHENS \\ Utah State University
}

In response to criticism that they do not train students to be effective decision makers, many business schools have attempted to modify their graduate management programs. We suggest that a primary ingredient missing from these attempts is a comprehensive treatment of systemic thinking. While most business functions teach about the systems housed within them, we suggest that few teach their students to think systemically. We propose a 3-part description of systemic thinking and provide results of a survey that investigates the claim that students are not being taught to think systemically.

Recent trends raise concerns that traditional approaches to educating and grooming future business leaders may be insufficient. For example, product life cycles are rapidly decreasing, and in some industries, are now measured in months (Fine, 2000). Product and process innovations are quickly diffusing throughout industries to become standard practice (Gharajedaghi, 2005; Morris, 2003). New technology is making it easier for companies, regardless of location, to compete globally, and the development of business ventures in nonindustrialized nations has significantly increased, adding to the competition in many industries. Every indication is that these trends will continue. More and more companies are participating in benchmarking and business-partnering programs, accelerating the rate at which organizations learn and trade upon new ideas and practices. Improvements in information technology are also making it easier to communicate these ideas, increasing the rate at which they are implemented both within and across industries. In addition, economic development in countries with weak enforcement of copyright and patent laws makes it difficult to prevent unauthorized use of legally protected intellectual capital and product and process technology. As a result, the time managers have to gather and process information, consider the implications of various alternatives, and make decisions, is shrinking.

As the business environment continues to evolve, it is important to assess how effectively managers are being prepared to face these everincreasing challenges. Unfortunately, empirical evidence suggests that managers are not adequately prepared. There are daily financial reports from Wall Street showing that companies are failing to perform as expected. Poor performance has resulted in a high turnover rate among upper-level executives; the average tenure of new CEOs is only about 18 months (Charan, 2005). In the year 2000 alone, 40 CEOs of Fortune's top-200 companies were fired or asked to resign (Bossidy \& Charan, 2002). For every successful new business there are 22 failures. For those that do survive the start-up phase, their average lifespan is only 11.5 years. The performance of the best organizations is not much better. A recent study showed that an average of 30 companies drop off the Fortune-500 list every year, and the average life of firms on the S\&P 500 is only 25 years (Morris, 2003)!

Claims that academic programs in business do not adequately prepare graduates for the "real world" are not new. Harvard Business Review published an article on the subject as for back as 30 years ago (Livingston, 1971). Since then, several articles have been published on the topic, each offering different criticisms and recommendations (e.g., Dertouzos, Lester, \& Solow, 1989; Porter \& McKibben, 1988; Steiner \& Wells, 2000; Mintzberg \& Gosling, 2002; Pfeffer \& Fong, 2002, Ghoshal, 2005; and Bennis \& O'Toole, 2005). The question remains: "How should a graduate business curriculum be 
designed to prepare business leaders to be successful in the 2lst century?" Moreover, it is a question several academic institutions are asking (Bisoux, 2005).

A specific criticism of business curricula is that they are too functionally isolated and fail to provide students with an understanding of how the parts of an organization work together. The idea that businesses should be studied and understood as a single entity rather than as a collection of functional parts is often referred to as the systems view of organizations. During the last decade of the 20th century, several well-respected management experts published books and articles emphasizing that businesses are complex social systems, and that management practices must change to be effective in this environment (Senge, 1990; Ackoff, 1994; Deming, 1994; Forrester, 1994).

At first glance it appears that universities have heard the criticisms and embraced the experts' recommendations. Indeed, the systems concept has become omnipresent in business programs. For example, students are taught about production systems, accounting systems, and information systems. Many schools have gone a step beyond, integrating material from different functional areas. However, the question is whether this is enough to prepare managers to be successful in what some are calling the systems age. The underlying premise of this study is that management education must go beyond merely teaching students about systems or integrating topics. It must help them develop systemic thinking skills that will enable them to develop a richer understanding of the complexity they will face on a daily basis.

We emphasize that the position taken here is not an indictment of current teaching practices. There is no question students must learn about systems. Studies have shown that a student's acquisition of operational skills is heavily dependent on the conceptual knowledge they acquire at earlier stages of their education (Wickens, 1992). Consequently, students must first be made aware of how businesses fit the systems paradigm, and what types of subsystems are embedded within them. They also need to learn about the various elements making up the different types of subsystems in a business, along with how they work and interact. Our position, however, is that while learning about systems and thinking about business from a systems perspective is critically important for students of business, this is not the same as thinking systemically, and that the development of systemic thinking skills is an essential evolution in management education.

Thus, we have three objectives. The first is to present the case for why the development of systemic thinking skills is a necessary process in the evolution of graduate management education. This is accomplished by examining the alternative paradigms of thinking that have emerged within business and industry and demonstrating their relationship to shifts in the systems view of the firm itself. The second is to investigate the role systemic thinking currently plays in graduate management education. While it is generally believed by scholors within the systems thinking community that systemic thinking is not widely taught in business curricula, no formal research effort has been carried out to confirm this belief. We present details of a survey that was conducted to explore if, and how, systemic thinking is being taught in the premier MBA programs in the United States. The third objective is to provide some suggestions that could help increase the understanding and coverage of systemic thinking in business curricula.

\section{EVOLUTION OF THE SYSTEMS PERSPECTIVE}

While the systems view of the world can be traced back to the early Greeks (von Bertalanfy, 1969), the emergence of a distinct discipline, systems science, that examines systems from a scientific perspective, did not emerge as a field until World War II, when, in an effort to solve complex problems, experts from a variety of fields were brought together. From its very beginning, the discipline has been multidisciplinary in nature. As such, it has evolved due to the insights of a wide variety of people. It is beyond our scope here to identify all the major contributors to the field. Readers are, however, referred to Leonard and Beer (1994) and Umpleby and Dent (1999) for excellent overviews of the major contributions to the field.

Understanding systems behavior is particularly important in today's businesses, which have evolved into multiminded, multipurpose, social systems. A review of the evolution of the systems view of a business helps clarify this point. ${ }^{1}$ Businesses were originally viewed as being similar to mechanistic systems. This was a direct result of analytical thinking. Through the use of principles such as scientific management, work was broken down into simplified parts. Employees were assigned simple tasks, and as a result, were viewed and treated like interchangeable machine parts.

Over time, the systems view of a business shifted from a mechanical perspective to a biological one.

\footnotetext{
${ }^{1}$ For an excellent in depth discussion of the evolution of the systems view of a business see Gharajedaghi, 2005.
} 
This arose as a result of business owners using equity financing to fuel the growth of their organizations. As ownership of the business diffused, managers, rather than owners, became responsible for running organizations. A management hierarchy developed and a divisional structure was created to enable the various functions to grow with the business. The analytical perspective still applied since it was believed that a business would perform optimally if each function tried to optimize its performance in isolation from the other functions. This hierarchical arrangement and divisional structure became widely used and remains the dominant approach employed to organize businesses, business schools, and business school curricula.

As businesses continued to grow and each functional area pursued excellence in isolation, conflict between functions began to emerge. Shortages of shared resources and inconsistencies across functional performance measures were just a few of the issues that created these conflicts. Furthermore, a variety of social changes forced managers to become aware of other stakeholders in their business. In addition to shareholders and customers, managers needed to address the concerns of employees, suppliers, government agencies, special interest groups, and society at large. These conflicts between functions, compounded by social change, resulted in another shift in the systems view of business. Organizations are now recognized as being part of a larger purposeful system (i.e., society) with many subsystems (functional areas and or teams) and parts (employees) all seeking to fulfill their own individual purposes.

Several recent articles have noted that the failure of education programs to address this last shift is at the heart of many of the problems surfacing in business today. Ackoff and Gharajedaghi (1996) assert that many of the problems seen in business and other social systems are due in part to managing social systems as if they were mechanical or biological. Ghoshal (2005: 81) criticized business schools and businesses for assuming away the complexities of what he termed human intentionality, specifically asking: "Why don't we actually acknowledge in our theories that companies survive and prosper when they simultaneously pay attention to the interests of customers, employees, shareholders, and perhaps even the communities in which they operate? Bennis and O'Toole (2005: 3) noted that a common weakness of business research is that "the thing routinely ignored by academics on the grounds that they cannot be measured-most human factors and all matters relating to judgment, ethics and morality-are ex- actly what make the difference between good business decisions and bad ones."

If the various objectives of business, its subsystems, and its parts, are not recognized and properly managed, organizations will experience a great deal of interfunctional conflict. Effective management of a multiminded, multipurpose social system requires managers to understand the motivation behind the behavior of the various elements of that system. Understanding why the parts of the system behave as they do enables managers to appreciate the concerns of the various subsystems. By acknowledging and acting on these concerns, managers mitigate the fears of their constituent interests, who may view their concerns as being undervalued, or worse trivialized. In addition, managers should communicate why they are taking specific actions. The process of learning, acknowledging, and explaining the "why" behind behavior is essential in a social system to foster an environment in which managers have the latitude to change the relative priorities of objectives over time and is a key element of approaches such as participative management and policy deployment.

\section{WHAT IS SYSTEMIC THINKING AND WHY IS IT IMPORTANT?}

What exactly does it mean to think systemically? Unfortunately, there is not a simple answer to this question. Ackoff (2004: 4) acknowledged this difficulty when he provided the definition, "Systemic thinking is holistic versus reductionistic thinking, synthetic versus analytic." While this definition is accurate, it is not precise. It defines the concept but fails to help us understand what cognitive processes are encompassed in thinking systemically. When experts such as Ackoff define systemic thinking, they are no doubt implicitly including these processes. However implied processes are of little use from a pedagogical perspective. If educational programs are to help students learn to think systemically, these cognitive processes must be identified explicitly and students must be exposed to techniques that will help them develop the corresponding skills. A specific description of the skills that make up systemic thinking is thus needed and was developed for this research. It is based on the integration of ideas from several researchers in systems theory, and focuses on the cognitive processes needed to develop a holistic insight into a situation and to understand the implications of decisions that will alter the status quo. 


\section{Elements of Systemic Thinking}

The difficulty in describing systemic thinking is that it encompasses multiple skill sets. By necessity, therefore, the description is developed in parts. ${ }^{2}$ The first element is rooted in the concept of holistic/synthetic thinking implicit in Ackoff's definition. Ackoff (1981) explained that for the past 400 years we have been trained using the analytical paradigm. Consequently, we view analysis and thinking as being synonymous. In reality, analysis is only one method of perceiving the world around us. Ackoff differentiates between synthetic (holistic) thinking and analytical thinking. Analytical thinking attempts to understand a system by breaking it into smaller parts and studying them in isolation. Once the parts are understood, the analyst attempts to explain the behavior of the whole based on the behavior of the parts. In contrast, synthetic thinking attempts to understand the larger context that the system operates within. Once the role of a system within this context is understood, the synthetic thinker tries to explain the behavior of the system based on that role. In other words, analytical thinking explains what the parts do and how they work while synthetic thinking explains why the parts do what they do. Ackoff points out that when a system is disassembled it loses its essential properties and so do its parts. Furthermore, he argues that observation of the interaction between and among the parts is crucial to understanding system behavior. Consequently, he maintains that it is impossible to fully understand a system through analysis, thereby making the case for developing synthetic/holistic thinking skills.

While holistic thinking is an essential element of systemic thinking, it does not completely describe the cognitive processes necessary to think systemically. Forrester (1971) identified several characteristics of complex systems, which make it difficult for people to understand and work with them. These include the following:

- Cause and effect are often separated in both time and space.

- Problem resolutions that improve a situation in the short term often create larger problems in the long term, and actions that make things worse in the short term often have long-term positive effects.

- As a result of the first two characteristics, people often fail to learn from their mistakes.

- Long time delays often result in one per-

\footnotetext{
${ }^{2}$ The irony of using an analytical process to define systemic thinking is not lost on the authors.
}

son creating a cause and another experiencing its effect.

- Due to differences in short- and long-term effects; what a person learns from the short-term result of a decision may be different from the true long-term outcome.

- Subsystems and parts of a system interact using multiple, nonlinear feedback loops. This complex flow of interactions often creates counterintuitive behavior. Consequently, what appears to be the obvious "right" decision is in fact often a bad choice!

Note that the factors identified by Forrester focus on time and on complex interactions. A complete description of systemic thinking must, therefore, include an understanding of these phenomena.

It is not uncommon for decision makers to overlook the phenomena described above when making decisions, and indeed many do not realize they exist. The concept of cause and effect is generally learned at an early age through simple situations. If I touch a hot stove I get burned. If I don't watch where I am walking I will stumble over something, and so forth. These simple situations condition us to develop an event-oriented view of the world (Sterman, 2000). We perceive the world as a series of cause-and-effect relationships in which on effect has a single cause that occurred shortly prior to the effect surfacing. This perception, in turn, prompts us to treat problems as isolated events and to solve them using a discrete, linear process of problem recognition, identification of alternatives, selection and implementation of solutions that lead to problem resolution. While this may work with simple systems, it oversimplifies the solution of problems associated with complex social systems. Parts of a social system all have objectives and are constantly interacting. Because of the interdependency of the parts, changes cannot be made in isolation. Moreover feedback loops can create unintended consequences that do not follow a simple linear course and commonly include time delays. Senge (1990: 57) articulated the common misperception of event-oriented thinking succinctly in his classic book The Fifth Discipline, stating, "Today's problems come from yesterday's solutions."

Richmond (2000) defined two types of thinking related to the phenomena described by Forrester. Dynamic thinking describes a decision maker's ability to see a phenomenon as the result of behavior over time rather than a reaction to an isolated event. Closed-loop thinking requires the decision maker to examine the role that the structure of the system (i.e., performance measures, reward systems, and information flows) plays in creating 
behavior. It also examines interactions of the system with external forces. Once the structure and interactions are recognized, closed-loop thinking seeks to provide an understanding of how these interactions feed back to shape the ultimate result of an intervention.

Synthesizing the above discussion, we propose that from a pedagogical perspective, systemic thinking should be defined using the following elements:

- Synthetic Thinking: Studying the role and purpose of a system and its parts to understand why they behave as they do.

- Dynamic Thinking: Examining how the system and its parts behave over time.

- Closed-Loop Thinking: Investigating how the parts of a system react and interact to each other and external factors.

Because people generally have on eventoriented view of the world, they do not readily apply systemic thinking skills. In fact, Forrester (1971) asserted that the human mind is incapable of truly understanding the behavior of complex social systems without the assistance of tools and technology. Booth, Sweeney, and Sterman (2000) tested Forrester's claim by developing on inventory of exercises designed to examine people's ability to recognize and anticipate the results of systemic interactions. Participants performed poorly even on the simple tasks. For example, in one exercise participants were asked to draw a simple graph approximating how the level of water in a bathtub would change over time as the rate of inflow and outflow was varied. The authors were surprised to find that even students with advanced degrees in math and physics had difficulty completing this exercise correctly. Not surprisingly, the performance of the participants got worse as the complexity of the exercises increased.

Other studies have further verified that most people have extreme difficulty conceptualizing behavior over time and anticipating the impact of feedback loops (Dorner, 1996; Ossimitz, 2002; Pala \& Vennix, 2005). Furthermore, these studies also indicated that this difficulty transcends age, national origin, educational background, and other demographic variables. The implication from these studies is that people must be trained in the principles, concepts, and tools of systemic thinking in order to understand and work effectively with and within complex social systems.

\section{TEACHING THE ELEMENTS OF SYSTEMIC THINKING}

What does it mean to teach people to think systemically? In reality, no one teaches another per- son how to think. People can, however, be taught tools and techniques that focus thinking processes in a specific way. For example, the scientific method helps researchers isolate variables and study how they impact a phenomenon of interest. Over the years virtually every field has developed its own set of analytical thinking tools. Similarly, the field of systems thinking has developed specific tools to help people think systemically. Several tools have been developed to facilitate an understanding of how parts of a system interact. For example, value stream mapping was developed within the lean manufacturing community to trace workflows and differentiate value-adding from nonvalue-adding activities. In the field of accounting, the balanced scorecard was developed to help managers simultaneously assess the performance of a business across multiple dimensions. Policy deployment, a tool of strategic management, facilitates an understanding of how various initiatives can be deployed horizontally and vertically within an organization. However, while these tools are useful for helping managers think holistically, they do not address feed back loops and behavior over time. To accomplish this requires the use of tools such as causal loop diagrams and stock and flow maps.

The causal loop diagram (CLD) illustrates the feedback structure within a system (Sterman, 2000). A CLD is useful for communicating the mental models individuals or teams have about how actions feed back through a system. As individuals learn to develop CLDs, they are better able to organize and articulate their own thoughts about system behavior, as well as to develop a richer understanding of true dynamics of the system. Moreover, the development of CLDs helps individuals avoid the oversimplification that typically occurs in attempting to explain complex system behavior. An example of a simple CLD is provided in Figure 1. Note that the example is a reinforcing loop, which means that each cycle increases the

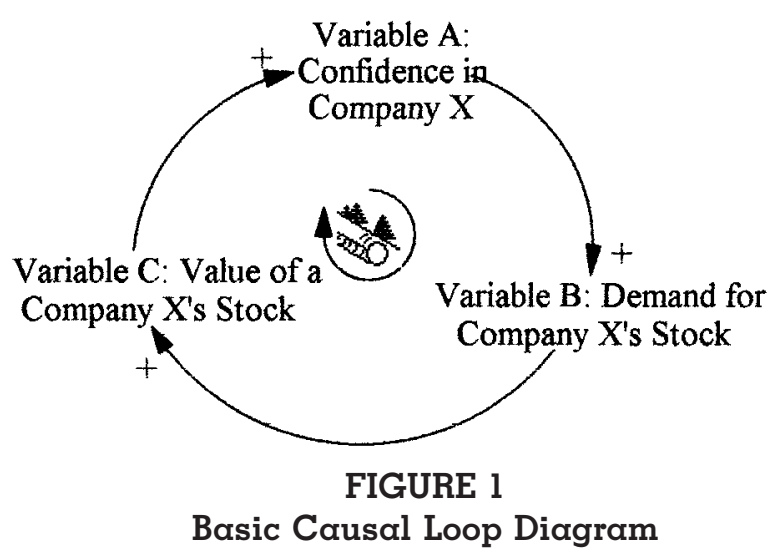


variables in the loop. The plus sign on the arrow means that the variables linked by the arrow change in the same direction (i.e., if variable $A$ goes up variable B also goes up). A minus sign means they change in opposite directions (i.e., if variable A goes up variable B goes down). You can start with any variable to read through the loop. For example, starting with variable $A$, as confidence in company $\mathrm{X}$ increases, demand for company $X^{\prime}$ 's stock increases, which in turn increases the price of company X's stock. The increase in price serves to further bolster confidence in company $X$, and so forth. ${ }^{3}$ Of course, many other aspects may impact this CLD model, but a detailed discussion of CLDs is beyond our scope here.

System archetypes make use of the CLD tool. These archetypes are generic structures representing specific combinations of feedback loops that commonly occur in a wide variety of complex systems (Senge, 1990). Once one is aware of the archetypes, it is often possible to recognize them at work within a particular system and use them to explain counterintuitive outcomes and identify leverage points for improving system performance.

There are currently nine archetypes identified and discussed in the literature. A detailed description of each is beyond our scope; however, an example of one of the most well-known archetypes "shifting the burden," using the Enron scandal is provided in Figure 2. ${ }^{4}$ This archetype has three causal loops. The top loop represents the scenario where an intervention does not actually solve the problem but only temporarily improves the situation. In the example provided, Enron's extensive use of limited liability partnerships (LLPs) helped the company's financial performance look better than it actually was. A second loop splits off from the top loop representing an unintended consequence for implementing the symptomatic Solution. The unintended consequence (which usually shows up after a period of delay) not only makes the situation worse, but it also makes it more difficult to implement the fundamental solution. In the Enron situation the unintended consequence was the loss of investor goodwill once their true financial performance came to light. The bottom loop represents pressure to implement the fundamental solution that addresses the root cause of the problem and will ultimately improve the situation. This loop may never actually surface. How-

\footnotetext{
${ }^{3}$ Note that the arrow connecting two variables represents $a$ causal relationship not a correlation.

${ }^{4}$ The diagram is obviously a simplified representation of the complex issues surrounding Enron.
}

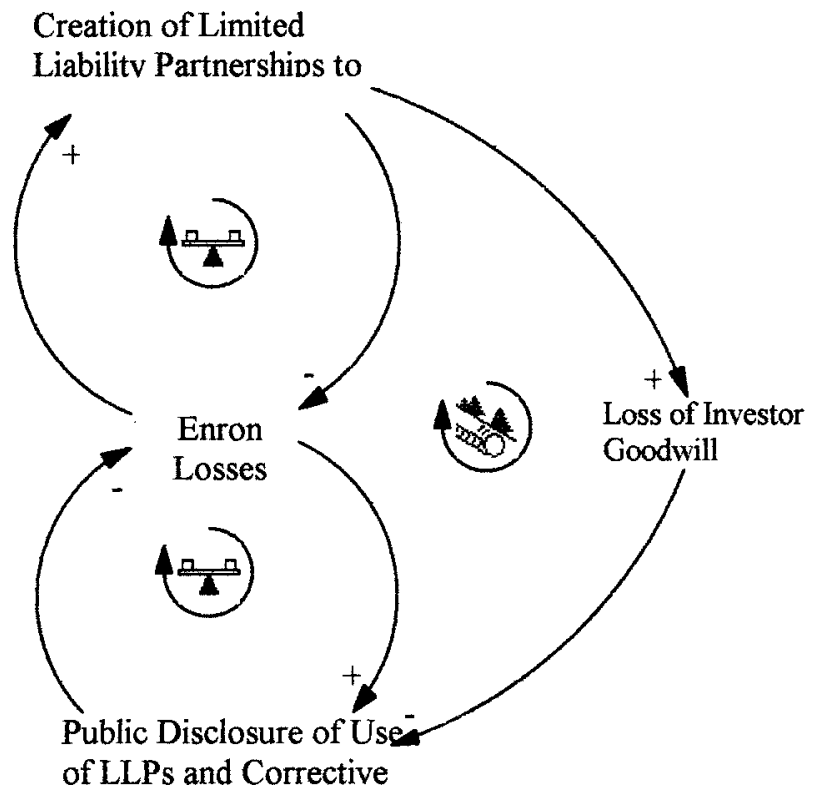

FIGURE 2

\section{Shifting the Burden Archetype, Enron Example}

ever, if it does it is usually after a substantial period of delay. In Enron's case, their efforts to correct the situation and regain investor confidence came too late.

Central to the understanding of dynamic system behavior is the fact that items move through a system and accumulate at various points. Virtually every business phenomenon can be described using stocks and flows (Sterman, 2000). For example in accounting, balance sheets represent stocks and income statements represent flows. In marketing, existing customers represent a stock into which new customers flow, and customers no longer using the product are an outflow. Stock and flow maps can be used to diagram this aspect of system behavior. A stock is represented by a rectangle, indicating a point of accumulation. Flows are represented by arrows that point into and out of $\alpha$ stock indicating inflows and outflows. In addition to helping people visualize how the structure of $a$ system explains behavior, these maps are the primary tool for building dynamic simulation models that demonstrate how a system might behave over

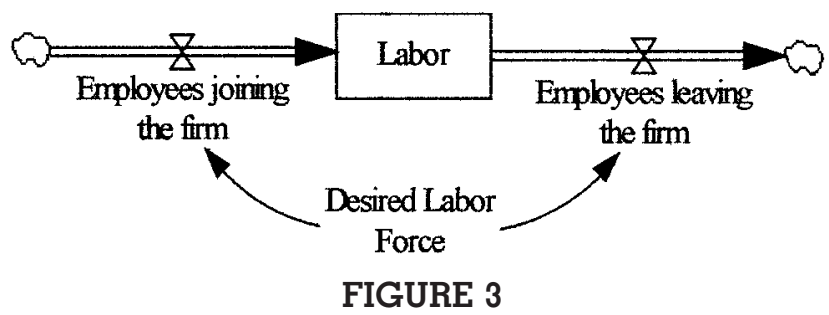

Stock \& Flow Diagram of Company Labor Pool 
time. A simple stock and flow map representing a company's labor pool is shown in Figure 3.

Each tool described above is designed to assist people in thinking systemically. They are not specific to any business function such as operations or accounting. As such, they can be used in a range of situations to provide insight into behavior of interest in a systemic way. Moreover, they enable managers to better understand the systems they work within, to communicate that understanding to others and facilitate the lifelong learning imperative for working in complex social systems. ${ }^{5}$ They also allow managers to articulate and incorporate the human intentionality that Ghoshal (2005), and Bennis and O'Toole (2005) criticize managers for leaving out of their decision making!

\section{THE CURRENT STATE OF SYSTEMIC THINKING}

\section{Survey Methodology}

Despite growing support that systemic thinking is a necessary skill for managers and that they need training to develop that skill, what role higher education is playing in facilitating this task is unclear. To date no scientific inquiry has been conducted to examine the teaching of systemic thinking in graduate business programs. To develop insight into the current state of systemic thinking education in business schools, a survey was conducted of faculty at the leading graduate business schools in the United States. The primary focus of the survey was to assess the awareness and perception business school faculty have of systemic thinking. Three specific questions were of interest:

- Do faculty understand what systemic thinking is?

- Do faculty believe systemic thinking has a place in graduate management education?

- Is systemic thinking being taught in graduate management programs, and if so, how?

To gauge respondents' understanding of systemic thinking without unduly influencing them, multiple potential definitions of the concept were sought. Discussions were conducted with faculty from a variety of business disciplines at the authors' institution to solicit insight into how they defined systemic thinking. In addition, textbooks in the different disciplines were reviewed to assess how they defined systems and a systems approach to their discipline. This analysis yielded

\footnotetext{
${ }^{5}$ For detailed description of these tools refer to Sterman (2000).
}

five alternative definitions of systemic thinking. The first, "eliciting multiple perspectives to understand a situation," incorporates the idea of taking a holistic approach to decision making by soliciting multiple inputs. However, it does not explicitly address complex interactions or feedback loops, both of which can be easily overlooked even when seeking multiple inputs. In addition, it does not address the issue of time delays. The second presents the classic operations research view of system optimization and is valuable when dealing with mechanistic systems in which parts behave in predictable ways. However it loses relevance when applied to complex social systems with nonlinear feedback, and is thus inadequate for most managerial situations (Ackoff, 1979). The third explicitly discusses the concept of interaction between system parts. While it addresses one of the key aspects of systemic thinking, it again fails to address concepts of feedback and time delays. The fourth, drawn from the field of process improvement, reflects a more holistic perspective of processes that facilitates recognition of interactions between parts within and external to the system of interest. However, it again fails to address the time dimension. The fifth definition is the most complete. It incorporates both feedback loops and behavior over time. One weakness, however, is its omission of interactions with, and feedback from, external forces. Nevertheless, being the most complete definition of those provided, its selection over others suggests that respondents recognize that systemic thinking is composed of multiple aspects. It should be noted that while none of the definitions incorporates all the elements discussed earlier, one is closer to our description than others.

Respondents were also given the opportunity to provide their own definition. In addition, respondents were asked a number of questions relating to their perceptions of how important systemic thinking is to graduate management education, where they believed systemic thinking belongs in the curriculum, where in the curriculum, if at all, they believed it was being taught, and which tools were being used to do so.

The survey instrument was pretested by faculty at the authors' institution. Based on this, a number of questions were reworded to improve clarity and to ensure that respondents' interpretation of the questions was consistent with the authors' intent. The revised instrument was further pretested by several respondents outside the authors' institution. Pretest data was not used in the subsequent data analysis. The final survey instrument was distributed electronically to 3,14l faculty members 
TABLE 1

\section{Defining Systems Thinking}

\begin{tabular}{|c|c|c|}
\hline Definition Responses & Number & $\begin{array}{l}\text { Percent of } \\
\text { Total }\end{array}$ \\
\hline $\begin{array}{l}\text { 1. Eliciting inputs from multiple disciplines \& perspectives to develop a more } \\
\text { complete understanding of a situation }\end{array}$ & 48 & 16.2 \\
\hline $\begin{array}{l}\text { 2. Identifying the optimal combination and arrangement of resources needed } \\
\text { to achieve a desired outcome }\end{array}$ & 38 & 12.8 \\
\hline $\begin{array}{l}\text { 3. Studying how the different parts of an organization interact to achieve a } \\
\text { desired outcome }\end{array}$ & 56 & 18.9 \\
\hline $\begin{array}{l}\text { 5. Understanding how different parts of an organization interact, react to } \\
\text { change over time, \& send feedback to affect performance }\end{array}$ & 105 & 35.4 \\
\hline \multicolumn{3}{|l|}{ 6. Other } \\
\hline a. Never heard of systemic thinking/have no idea how to define it & 17 & 5.7 \\
\hline b. All of the above & 9 & 3.0 \\
\hline
\end{tabular}

at the top 63 graduate schools of management ${ }^{6}$ in the United States. The rationale for focusing on the leading business schools is that these schools are at the forefront of management education, and thus, these institutions would be among the more likely to recognize the need to incorporate systemic thinking into their curricula. To obtain a data set representative of a cross-section of business disciplines, proportionate stratified sampling was used based on faculty disciplines as identified from school Web sites. Respondents were, however, asked to report their actual area of expertise. An e-mail was sent describing the study, soliciting responses, and directing respondents to the Web site containing the survey instrument. Consistent with standard survey protocol (Dillman, 1999), respondents were sent an e-mail reminder 2 weeks later, and a second e-mail with instructions for completing the survey 2 weeks thereafter.

Two hundred and eighteen e-mails were returned undelivered, the remaining 2,922 yielded 297 useable responses, a response rate of just over $10 \%$. One response came from a faculty member whose discipline was outside business and was thus omitted from subsequent analysis. One third of responses came from assistant professors, 18\% from associate professors, and 37\% from full professors. Full-time faculty members accounted for 92\% of respondents. All business disciplines were represented within the respondent pool. Re-

\footnotetext{
${ }^{6}$ Rankings from five different sources were used to identify the top-50 business schools in the United States: BusinessWeek, the Wall Street Journal, U.S. News \& World Report, the Financial Times, and the Consus Group. As a result, a total of 63 schools were identified.
}

sponses were evenly distributed across disciplines with the exception of operations research and information systems. The small number of responses from these disciplines is, however, attributable to relatively fewer faculty members in these disciplines rather than to a low response rate. Response rates across disciplines were largely similar.

\section{Faculty View of Systemic Thinking Definition}

While results show that a large percentage of faculty recognize the multiple dimensions of systemic thinking, the majority (60.3\%) do not know what it is or define it unidimensionally (see Table 1). More than half $(54.6 \%)$ selected definitions one, two, three, or four, all of which reflect a one-dimensional perspective. Almost $6 \%$ of respondents admitted they had never heard of systemic thinking and could thus not define it. One went further, stating, "It sounds like just another empty management research buzzword to me." Definition five was the single most frequently selected, yet it was selected by only $35 \%$ of the respondents. Selecting other definitions does not, however, imply that respondents do not have a sound understanding of the concept. A respondent may have, for example, selected option 1 and inferred a time, interaction, or feedback dimension. However, the fact that these dimensions were included in option 5 , which they did not select, does suggest a less-than-complete view of systemic thinking. The implication is that the challenges inherent in increasing the coverage of systemic thinking in graduate management programs may go beyond enlightening faculty who are unaware of the concept. It may also involve raising awareness among faculty of all the 
elements of systemic thinking. Given the impact of feedback loops and time delays on system behavior and a manager's limited ability to reason through how the actions play out, it would seem to be a major oversight to leave them out of a manager's education.

Two follow-up questions further assessed faculty perceptions of systemic thinking. Respondents were asked how strongly they agreed with the statement, "Teaching students to think systemically is an essential part of a graduate business program." In addition, they were asked if systemic thinking skills were taught in their institutions' graduate business programs. Since it was felt that there could be a relationship between a respondent's answers to these questions and the way they defined systemic thinking, the responses were stratified accordingly (see Table 2).

TABLE 2

Importance of Systemic Thinking and Whether It Is Being Taught

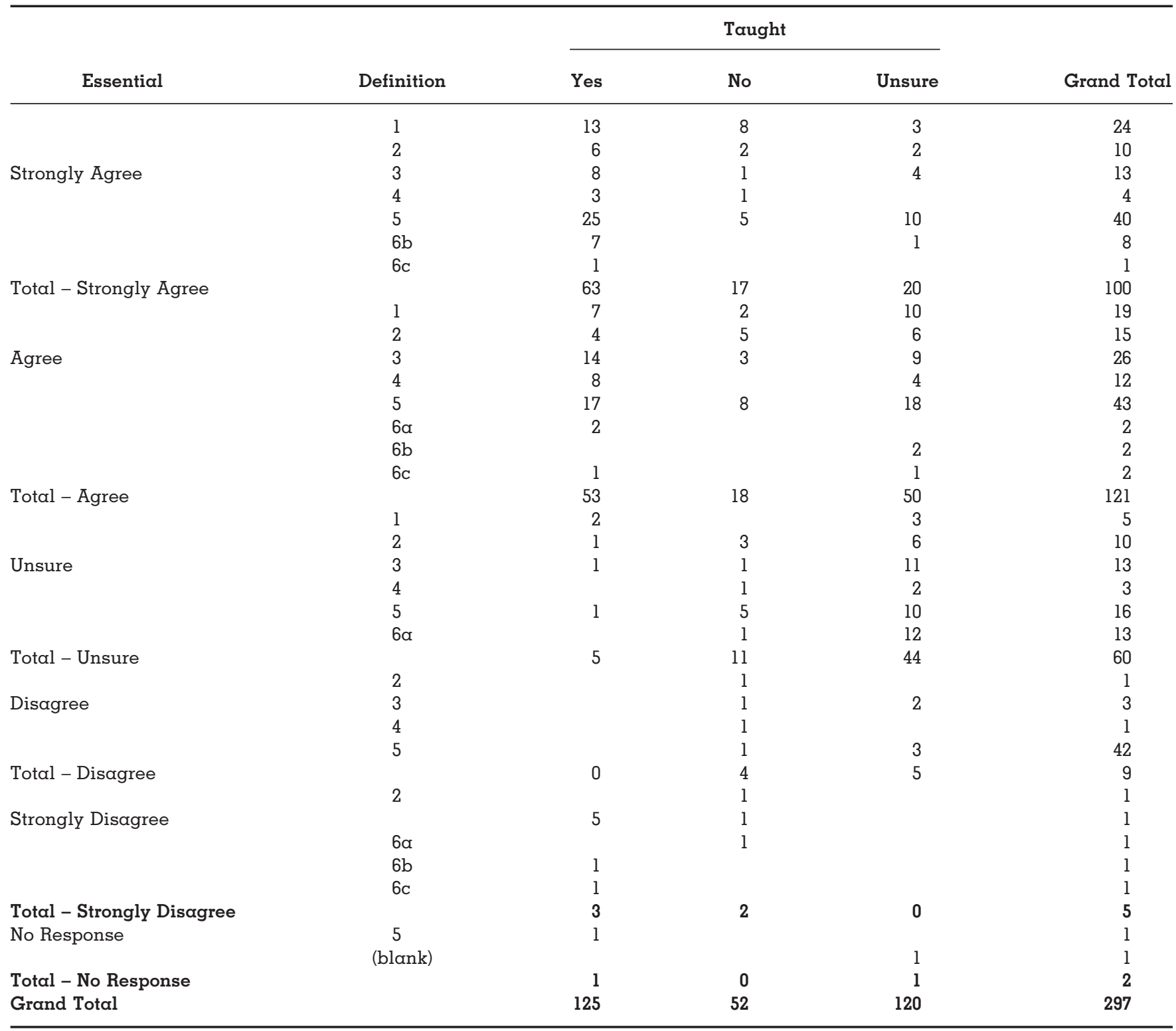

1 = Eliciting inputs from multiple disciplines and perspectives to develop a more complete understanding of $a$ situation; $2=$ Identifying the optimal combination and arrangement of resources needed to achieve a desired outcome; $3=$ Studying how the different parts of an organization interact to achieve a desired outcome; 4 = Mapping work flows to determine how information and material cut across an organization to create value; 5 = Understanding how different parts of an organization interact, react to change over time, and send feedback, to affect performance; $6 a=$ Respondent provided definition indicating they were unfamiliar with concept; $6 \mathrm{~b}=$ Respondent provided definition embracing multiple definitions; $6 \mathrm{c}=$ Respondent provided definition embracing multiple definitions AND external environment. 
While there were differences across definitions, the vast majority of respondents $(74 \%, 221 / 297)$ agreed or strongly agreed that systemic thinking is an essential part of a graduate management education. Despite this, however, nearly half the respondents that felt it is an essential topic in graduate curriculum (105/221) were either unsure or felt it was not being covered. If one considers systemic thinking to incorporate the impact of feedback, interactions, and time delays, this number may in fact be an underestimate. It is quite possible that those who define systemic thinking unidimensionally and say they are teaching it, are leaving out important elements of it. Regardless of how these numbers are analyzed, they raise the question of why such a large percentage of faculty who feel systemic thinking is essential either believe it is not being covered or are unsure if it is. A simple explanation could be that some faculty feel systemic thinking is essential, but that it should be taught in classes other than their own. Consequently, they cannot be certain it is covered. While the same is true for tools such as statistics or calculus, most programs do not leave their coverage to chance.

Another important observation is that several respondents that defined systemic thinking in a fairly complete, multidimensional way (i.e., definition 5 , or respondent definitions $6 \mathrm{~b}$ or $6 \mathrm{c}$ ) did not feel it was essential. Sixteen respondents were unsure if systemic thinking was an essential element of the curriculum, four disagreed that it was essential, and two strongly disagreed. While the numbers are small we feel they are significant. It is hard to imagine anyone, let alone faculty at the leading graduate business schools, arguing with students in a graduate-level business program being provided with the best tools possible to address problems that are complex, dynamic, crossfunctional, and with multiperiod implications. Consequently, it seems reasonable that there must be another explanation for these seemingly dichotomous responses. Whatever the explanation, both findings raise an important question: "Why isn't systemic thinking more widely taught in management curriculum?"

\section{How Faculty Teach Systemic Thinking}

To better determine if faculty are teaching systemic thinking in a manner that incorporates the dimensions of time and feedback loops, respondents were asked if they taught systemic thinking in their classes. Respondents that said they did were referred to a list of systems-related topics and tools common to their chosen field and asked to identify which ones they used to teach the concept. The lists were made up predominantly of tools that help decision makers take a more holistic perspective of systems. For example, the list for operations management included items such as lean production systems, supply chain management, value stream mapping, fishbone diagrams, and the define, measure, analyze, improve, and control (DMAIC) cycle. The list for accounting included the balanced scorecard, data flow diagrams, associative databases, and entity relationship maps. In addition to discipline-specific items, each list also included the tools described earlier (i.e., causal loop diagrams, and stock and flow maps) since these are designed specifically to help people understand the impact of feedback loops and time delays on system behavior. Respondents were also given the option to list tools they used that were not included in the lists provided.

A number of observations can be made from the results shown in Table 3. First, about 31\% (92/297) of respondents state that they teach systemic thinking. Second, every functional area has at least some faculty teaching systemic thinking, and some teaching causal loop diagrams or stock and flow maps. Third, at least 35 different schools had one or more faculty member indicate that they taught systemic thinking in their classes. Within the systems thinking community it is generally believed that systemic thinking is not widely tought. In general, the results of the survey support that belief. However, they also show that the concept has permeated virtually every functional area of business, and is taught, in one form or another, at most of the top-ranked schools. Finally, of the 92 respondents that indicated that they taught systemic thinking, only 41 had previously selected a

TABLE 3

Faculty Teaching Systemic Thinking and Those Using Causal Loop Diagrams or Stock and Flow Maps in Their Classes

\begin{tabular}{lcccc}
\hline Expertise & $\begin{array}{c}\text { No. Teaching } \\
\text { Systemic } \\
\text { Thinking }\end{array}$ & $\begin{array}{c}\text { No. } \\
\text { Using } \\
\text { CLD }\end{array}$ & $\begin{array}{c}\text { No. } \\
\text { Using } \\
\text { S\&F Maps }\end{array}$ & $\begin{array}{c}\text { No. } \\
\text { Using } \\
\text { Both }\end{array}$ \\
\hline Accounting & 14 & 1 & 1 & 1 \\
Economics & 8 & & 1 & 1 \\
Finance & 8 & 2 & 1 & 3 \\
HR/OB & 13 & 2 & & \\
IS & 4 & 3 & 1 & 4 \\
Marketing & 11 & 2 & & 2 \\
POM & 19 & 2 & & 1 \\
OR/MS & 3 & 12 & 9 & 2 \\
Strategy & 12 & & & 14 \\
Grand Total & 92 & & & \\
\hline
\end{tabular}


definition of systemic thinking that incorporated its multiple dimensions (i.e., definition 5 or respondent-provided definitions $6 \mathrm{~b}$ or $6 \mathrm{c}$ ). This provides additional support that some faculty who believe they are teaching systemic thinking may not be addressing all of its dimensions.

\section{CONCLUSIONS AND RECOMMENDATIONS}

The good news is that systemic thinking has permeated the curriculum of many top business schools and virtually every functional area within business. Nevertheless, three issues of concern were raised by survey results. First, the majority of the faculty were either unfamiliar with systemic thinking or define it unidimensionally. Second, while the vast majority feels it is an essential part of a managers' education, almost half are unsure of its coverage in their curriculum or are certain that it is not covered. Third, several of the respondents defined systemic thinking to be synonymous with synthetic thinking, suggesting that many faculty are teaching systemic thinking yet may be leaving out its other important elements, such as dynamic and closed-loop thinking. We feel that these findings are interrelated. How faculty members define systemic thinking will affect their perceptions of its importance and its coverage. In the following paragraphs we offer some suggestions that could lead to increased coverage of systemic thinking concepts and tools. These suggestions are not meant to be presented as the answer to the problem, but we hope will serve to stimulate further discussion on this topic.

Our first recommendation, therefore, is to develop a unified understanding of the concept. The synthetic thinking element discussed by Ackoff is cleorly the most visible and readily recognized. This is likely a result of there being considerable material in a wide variety of publications on this element of systemic thinking. Unfortunately, materials discussing the other elements are not as widely disseminated (Repenning, 2003). The implication for faculty working in areas related to dynamic and closed-loop thinking is that they need to target a much broader range of outlets for their work.

The above recommendation requires a shift in thinking regarding what constitutes publishable research. This is not a call to relax the rigor requirements of good research, only the mind-set that tends to exist about the structure of good research. As Ackoff (1981) pointed out, we are all trained analysts. This has created a silo mentality where an idea that does not fit neatly within a specific functional area can be quickly dismissed based on lack of fit with the focus of a journal.
Furthermore, there tends to be a bias toward correlation-based research findings. This makes us suspicious of research that seeks to establish causation, the focus of much of the systems thinking research. Systems thinking research also often incorporates "soft" variables such as attitudes and beliefs since the motivation behind behavior is critical to understanding complex systems. These variables are not easy to quantify and measure. Consequently, they are generally excluded in normal business research, and those that try to incorporate them are seen as suspect.

All these biases have been previously recognized and criticized by other researchers, so this is not a unique call for a mind shift. It has long been recognized that the silo mentality often found in business is dysfunctional and that the functional areas of a business are actually interdependent rather than independent (Gharajedaghi, 2005). Christensen and Raynor (2003) pointed out the need for greater acceptance of causation-based research due to its necessity in developing good management theories. In addition, as noted earlier, Ghoshal (2005) and Bennis and O'Toole (2005) have both called for business researchers to incorporate human intentionality into their projects. Despite these and other calls for greater acceptance of such themes in business research, there has been little change in the literature. One possible explanation for this can be found by applying systemic thinking, and in particular the success to the successful archetype (Figure 4). This suggests that the structure of a system determines the success or failure of a given approach. In this case, the biases in business research described above have created a situation where there are a large number of journals that publish research meeting certain criteria and expectations, and fit a certain research paradigm. This creates a reinforcing loop. The increased number of outlets motivates researchers to develop their research skills in certain areas and to use certain methodologies, resulting in fewer people learning and applying other methods.

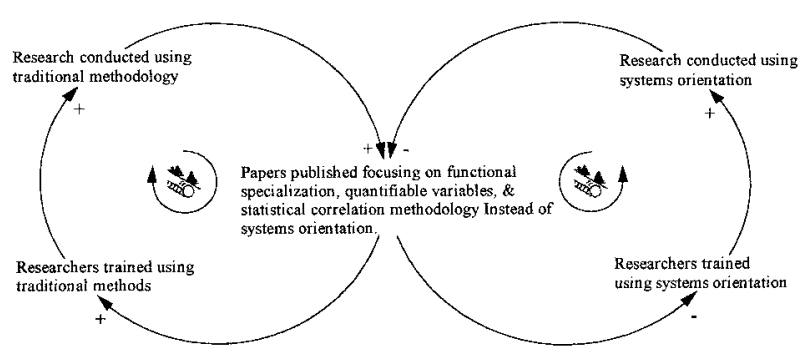

FIGURE 4

Success to the Successful Archetype Applied to Business Research 
As the number of faculty using the traditional approach grows, opportunities for upcoming researchers to learn alternative approaches decrease, since faculty at most institutions are unfamiliar with them and cannot teach them. In addition, the desire to learn and use alternative methods decreases because of the paucity of outlets willing to publish this type of research.

A small number of institutions do offer a new generation of researchers the opportunity to learn the systemic approach to research. Unfortunately, researchers using the systems approach have had difficulty getting work accepted in mainstream academic journals and are, as a result, limited in the range of institutions at which they can be successful. In response, they have developed their own research outlets, which have led to limited dissemination of the concepts and tools rather than the wide dissemination necessary to increase awareness and acceptance of systemic thinking. Moreover, they are limited to a small set of "believer" institutions. The result has been to create a small niche of faculty that has stayed primarily within itself (Repenning, 2003). To break out of these reinforcing loops in which traditional research methods grow stronger while systemic research remains small and isolated, participants in the dominant loop (i.e., traditional methods) must be willing to share the available resources (i.e., space in journals). As a starting point, some of the mainstream journals could devote a special issue to systems research in their specialty area. Hopefully, as systemic thinking concepts and tools become more widely published, they will be better understood, accepted, and used by business faculty.

Raising faculty awareness of systemic thinking to include all its elements is a starting point in addressing the first and third issues raised in the first paragraph of this section. However, the second issue of increasing its coverage in business curricula is more complex. When almost $75 \%$ of survey respondents indicate systemic thinking is an essential part of a manager's education, lack of a complete understanding of the concept does not explain its sparse coverage in business curricula. In fact, many faculty who felt it was essential and were unsure of its coverage defined systems thinking unidimensionally. Furthermore, there were those faculty who defined it fairly completely but felt it was not an essential part of management education. Unfortunately, the survey did not ask respondents to explain their positions so we can only speculate as to why they felt this way. As previously stated, it is hard to believe the responses are motivated by a belief that managers do not need tools to help them handle complex, cross-functional, multiperiod problems. The systems archetype, the tragedy of the commons, may offer a plausible explanation. In this archetype, a limited resource must be shared by two or more parts of the system. As the resource is consumed, less is available for future use. Eventually the resource is completely depleted to the detriment of the entire system. In the context of business curricula, the limited resource is credit hours. Every program has a finite number of credit hours that students must complete to earn their degree. It is generally necessary to keep the number within a specified range in order to be competitive with other programs. Consequently, it is not a simple matter to add another required course to the curriculum. Furthermore, every field of business continues to evolve, so new material constantly needs to be added to the curriculum. Unfortunately, older material is not dropped at the same rate. This dynamic creates conflict as the various disciplines struggle to control the limited number of credit hours to ensure adequate coverage of their subject matter. A topic that is beneficial to all, but not specific to any, will have difficulty in gaining control of resources since it may lack the requisite champion to fight for it. The tragedy of the com-

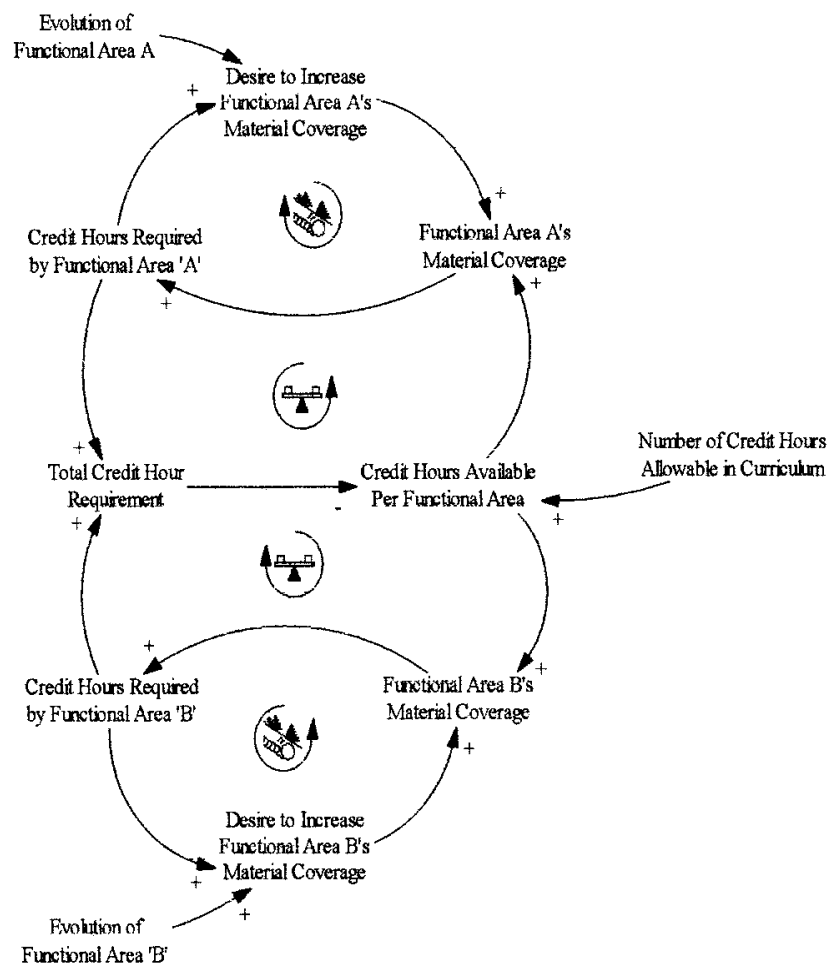

FIGURE 5

Tragedy of the Commons Archetype Applied to Business Curriculum 
mons archetype applied to this scenario is shown in Figure 5.

In the systems thinking literature, one method for addressing this archetype is to rethink the commons resource (Kim, 1994). Rather than addressing systems thinking in a single class and thus drawing from the limited number of credit hours, we suggest that it be incorporated into several courses. Survey respondents indicated that strategy, operations management, and operations research are the areas within business curricula with the strongest ties to systems thinking. Consequently, these areas may encounter the least resistance to the introduction of system thinking tools. Atwater and Pitman (2006) provide examples of how system thinking tools like CLDs and System Archetypes can be introduced and used to teach just-in-time production and supply chain management concepts in an introductory operations management class. However, while the crossfunctional nature of the disciplines mentioned lend themselves to the incorporation of systemic thinking approaches, virtually every area in the business curriculum could benefit from applying systemic thinking.

It is interesting to note that the survey indicated that a minority of faculty felt that systems thinking should be covered in accounting, marketing, economics, or finance courses. This suggests on opportunity to make stronger connections between systems thinking and these fields. For example, the growth and underinvestment system archetype, a classic model of behavior in complex systems within the systems thinking community, can be used to explain the well-known finance problem of rapid growth and financing. The People Express Case (Schlesinger \& Whitestone, 1983) is an excellent case for illustrating this concept. The systems dynamics community has developed several teaching supplements for this case, including a dynamic simulation game that students can play. The simulation incorporates hiring and marketing decisions, which makes the game suitable for teaching the systemic impact of decision making in these functional areas as well. One area that researchers within the systems community could assist in the dissemination of these ideas across the business curricula is to develop and market teaching materials for the core functional areas couched in the terminology of each discipline. This would help professors interested but unfamiliar with the concept to more easily incorporate them into their courses.

Finally, given the opportunities to apply systemic thinking across the virtually every functional area, we recommend that the tools be introduced in a required class early in the curriculum, for example in an introductory operations research or operations management class. Once students learn the tools, they should then be encouraged or required to apply them in subsequent courses in other functional disciplines. Ironically, this approach could even eliminate the continuous battle over limited credit hours. By teaching students methods that enable them to continue their education on their own, it becomes less imperative to cover "everything" within the curriculum. Professors can point students in a direction and let them teach themselves. Unfortunately, the urge to cover specific content in a course can make faculty unwilling to allocate precious class time to teaching self-education processes. However, the suggested approach would actually improve the learning experience. Students would gain better exposure to the use and value of systems thinking concepts while simultaneously gaining deeper insight into the topics covered in the course. Moreover, teaching students how to use the tools does not require a significant investment of time. Research has shown that even brief exposure to systems thinking concepts and tools can improve students' systems thinking skills (Kainz \& Ossimitz, 2002). Once the students have been exposed to the tools, they can use them to investigate any phenomenon of interest. The focus moves quickly from learning tools to using them to explain mental models of the subjects under discussion. The tools can be useful in helping students articulate their understanding, and subsequently help the professor correct misperceptions that often lay hidden from view.

The more likely obstacle to this approach would be resistance by professors who are unfamiliar with the tools and thus uncomfortable incorporating them into their classes. Here again the critical issue is one of exposure and familiarity. If coverage of systems thinking in graduate management curricula is to increase it is imperative that mainstream academic journals open their doors to researchers working in the area, and that system thinking researchers work to get published in a wider variety of journals.

Business academia continues to struggle with how to change programs to better prepare students for the complexity they will face as leaders. It is hoped that better coverage of systemic thinking will be part of these changes. However, before that can happen, confusion concerning systemic thinking must be addressed and awareness of its importance increased. The goal of this article has been to provide insight that will help with this. At the very least, it is hoped it will stimulate further discussion and research on this important topic. 


\section{APPENDIX}

1. What is the title of your position?

Instructor

Lecturer

Senior Lecturer

Research Fellow

Teaching Fellow
Assistant Professor

Associate Professor

Full Professor

Other - Please Specify

2. Are you a full-time faculty member?

$$
\text { Yes No }
$$

3. Please identify which of the disciplines listed below best describes your area of expertise:

Accounting

Economics

Finance

Human Resources/Organizational Behavior

Information Systems
Marketing

Operations Management

Operations Research/Decision Sciences

Strategy/Management

Other - Please Specify

4. Which of the following best describes how you would define systems thinking?

- Eliciting inputs from multiple disciplines and perspectives to develop a more complete understanding of an organization

- Identifying the optimal combination and arrangement of resources needed to achieve a desired outcome

- Studying how different parts of an organization interact to achieve a desired outcome

- Mapping work flows to determine how information and material cut across an organization to create customer value

- Understanding how different parts of an organization interact, react to changes, and send feedback to affect performance

- Other

Please indicate how strongly you agree with the following statements. Based on your answer, irrelevant questions will be disabled. They will appear to be grayed out.

5. Teaching students systems thinking is an essential part of a management program.

Strongly Agree $\quad$ Agree $\quad$ Unsure $\quad$ Disagree Strongly Disagree

Comments:

* If this question appears to be grayed out, you do not have to answer it. Please proceed to the next question.

6. Systems thinking should be incorporated to some degree in every class in a management program.

Strongly Agree $\quad$ Agree $\quad$ Unsure $\quad$ Disagree Strongly Disagree

Comments:

7. What area(s) of the curriculum do you feel is best suited to cover systems thinking? (Select all that apply)

Accounting
Economics
Finance
Human Resources/Organizational Behavior
Information Systems
Marketing

Operations Management

Management Science/Decision Sciences

Strategy/Management

Other

Please Specify:

8. To your knowledge is systems thinking taught in the management program at your institution?

Yes No Unsure

Comments:

* If you answered no or unsure to question 8 above, you do not have to answer questions 9-13. Based on your answer, irrelevant questions were disabled. They will appear to be grayed out.

9. The management program at your school does an adequate job teaching systems thinking.

Strongly Agree $\quad$ Agree $\quad$ Unsure $\quad$ Disagree Strongly Disagree

Comments:

10. Do any of the classes taught within your discipline teach systems thinking skills?

Yes

No

Unsure

Comments:

* If you answered no or unsure to question 10 above, you do not have to answer questions 11-13. Based on your answer, irrelevant questions were disabled. They will appear to be grayed out.

11. Which of the following best describes the requirements for systems thinking classes in your discipline?

- At least 1 of the classes covering systems thinking is required of all students getting a graduate management degree.

- Students emphasizing this area in their curriculum are required to take at least $l$ of the classes covering systems thinking. The courses are not available to students not emphasizing this discipline. 
- Students emphasizing this area in their curriculum are required to take at least lof the classes covering systems thinking. The courses are available to students not emphasizing this discipline as an elective.

- The classes covering systems thinking are available as an elective to students emphasizing this area in their curriculum. The courses are not available to students not emphasizing this discipline.

- The classes covering systems thinking are available as an elective to all students getting a graduate management degree.

- Comments:

12. Referring to your specific discipline below, please identify which tools/concepts are used to teach systems thinking (Select all that apply). Some sections of this question may appear to be grayed out. Those are the irrelevant questions that you do not have to answer.

Accounting
Enterprise Resource Planning
Balanced Scorecard
Causal-Loop Diagrams
Flowcharts/Process Maps
Data Flow Diagrams
Entity Relationship Map
Stock \& Flow Diagrams
Associative Databases
Other - Please Specify
Economics
Public Finance
Monetary Policy
Causal-Loop Diagrams
Comparative Economic Systems
Industrial Organizations
Stock \& Flow Diagrams
Game Theory
Simulation Modeling
Economic Policy
Other - Please Specify
Finance
Government Monetary Systems
Causal-Loop Diagrams
Banking System
International Financial Systems
Stock \& Flow Diagrams
Foreign Exchange
Money Markets
Other - Please Specify
Human Resources/Organizational Behavior
Strategic Planning
Policy Deployment/Hoshin Planning
Causal-Loop Diagrams
Equifinality
Stock \& Flow Diagram
Team Building
Other - Please Specify
Information Systems
Systems Development Life Cycle
Bnified Modeling Language Work
Data Flown Diagrams
Entity Relation

Diagrams/Matrices
Causal-Loop Diagrams
Rational Flow Diagrams
Stock \& Flow Diagrams
Other - Please Specify
Marketing
The Consumer Behavior Model
Causal-Loop Diagrams
Marketing Plan/Marketing Audit
Distribution/Logistics Management
Stock \& Flow Diagrams
Other - Please Specify
Operations Management
Value Stream Mapping
Ishikawa (Fishbone Diagrams)
Causal-Loop Diagrams
PDCA or DMAIC Cycle
Quality Function Deployment
Stock \& Flow Diagrams
Theory of Constraints
Lean Production Systems
Supply Chain Management
Other - Please Specify
Operations Research/Decision Sciences
Mathematical Programming
Dynamic Programming
Network Models
Simulation
Causal-Loop Diagrams
Multicriteria Decision Analysis
Stock \& Flow Diagram
Other - Please Specify
Strategy/Management
Strategic Planning
Policy Deployment/Hoshin Planning
Causal-Loop Diagrams
Equifinality
Stock \& Flow Diagram
Other - Please Specify
Other
Please Specify Area of Expertise
Please identify the tools used in the
spacelow:

13. If you teach systems thinking concepts, please refer to your specific discipline below and provide details of the resources you use. Please note that resources can be books, journal articles, or experiential learning exercises such as simulations, games, projects etc.

(For books and articles please provide the title, authors, journal title, and publication dates.) Some sections of this question may appear to be grayed out. Those are the irrelevant questions that you do not have to answer. Please scroll to find your active section.

Accounting

Books:

Articles:

Exercises:
Economics

Books:

Articles:

Exercises:

14. Please allocate 100 points across the following thinking skills according to their relative importance. 
- Analytical Problem Solving (The ability to break a problem into smaller more manageable parts for more in-depth understanding)

- Creative Problem Solving (The ability to use creativity tools to develop unique solutions to a problem)

- Systemic Thinking (The ability to understand how the interrelationships between the parts of a system impact its performance)

- Critical Thinking (The ability to ask insightful questions, make logical inferences, and assess the credibility of information)

- Other - Please Specify

Please feel free to provide any additional comments below:

\section{REFERENCES}

Ackoff, R. L. 1979. The future of operational research is past. Journal of the Operational Research Society, 30: 93-104.

Ackoff, R. L. 1981. Creating the corporate future: 3-26. New York, NY: John Wiley \& Sons.

Ackoff, R. L. 1994. The democratic corporation: A radical prescription for recreating corporate America and rediscovering success. New York, NY: Oxford University Press.

Ackoff, R. L. 2004. Transforming the systems movement. Keynote Address for International Conference on Systems Thinking in Management. Philidelphia, PA. Retrieved from http://www. acasa.upenn.edu/RLAConfPaper.pdf.

Ackoff, R. L., \& Gharajedaghi, J. 1996. Reflections on systems and their models. Systems Research, 13(1): 13-23.

Atwater, J. B., \& Pittman, P. H. 2006. Facilitating systemic thinking in business classes. Decision Sciences Innovation in Education, 4(2): 273-292.

Bennis, W. G., \& O'Toole, J. 2005. How business schools lost their way. Harvard Business Review, 83(5): 96-104.

Bisoux, T. 2005. The extreme MBA makeover. BizEd, May/June, $26-33$.

Booth Sweeney, L., \& Sterman, J. D. 2000. Bathtub dynamics: Initial results of a systems thinking inventory. System $D_{Y-}$ namics Review, 16: 249-286.

Bossidy, L., \& Charan, R. 2002. Execution: The discipline of getting things done, 13-34. New York, NY: Crown Business.

Charan, R. 2005. Ending the CEO succession crisis. Harvard Business Review, 83(2): 72-81.

Christensen, C. M., \& Raynor, M. E. 2003. Why hard-nosed executives should care about management mheory. Harvard Business Review, 81(9): 66-74.

Deming, W. E. 1994. Introduction to a system. In The new economics for industry, government, education: 49-91. Cambridge, MA: MIT Center for Advanced Educational Services.

Dertouzos, M. L., Lester, R. K., \& Solow, R. M. 1989. Made in America: Regaining the productive edge: 156-165. New York: HarperCollins.

Dillman, D. 1999. Mail and internet surveys: The tailored designed method, 2nd ed. New York: John Wiley \& Sons.

Dörner, D. 1996. The logic of failure: Recognizing and avoiding error in complex situations. New York, NY: Basic Books.

Fine, C. H. 2000. Clockspeed-based strategies for supply chain management. Production and Operations Management: 9(3): 213-221.

Forrester, J. W. 1971. The counterintuitive behavior of social systems. Technology Review, 73(3): 52-68.

Forrester, J. W. 1994. Learning through systems dynamics as preparation for the 21st century. Keynote Address for Sys- tems Thinking and Dynamic Modeling Conference for $\mathrm{K}-12$ Education. Concord, MA: Concord Academy.

Gharajedaghi, J. 2005. Systems thinking: Managing chaos and complexity 2nd ed. 3-27. Woburn, MA: ButterworthHeinemann.

Gharajedaghi, J., \& Ackoff, R. L.1985. Toward systemic education of systems scientists. Systems Research, 2(1): 21-27.

Ghoshal, S. 2005. Bad management theories are destroying good management practices. Academy of Management Learning and Education, 4(1): 75-91.

Kainz D., \& Ossimitz, G. 2002. Can students learn stock-flowthinking? An emprirical investigation. Proceedings of the 20th International Conference of the System Dynamics Society Polermo, Italy:

Kim, D. 1994. Systems archetypes II: Using system archetypes to take effective action, 24-25, Waltham MA: Pegasus Communications, Inc.

Leonard, A., \& Beer, S. 1994. The systems perspective: Methods and models for the future. Retrieved from http://www. futurovenezuela.org/_curso/6-sysmeth.pdf

Livingston, J. S. 1971. Myth of the well-educated manager. Harvard Business Review, January-February: 79-88.

Mintzberg, H., \& Gosling, J. 2002. Educating managers beyond borders. Academy of Management Learning and Education: $1(1): 64-76$.

Morris, L. 2003. Business model warfare: The strategy of business breakthroughs. An InnovationLabs White Paper published jointly with the Ackoff Center for Advancement of Systems Approach, Retrieved from http://www.innovationlabs. com/BusModelWarfare.pdf

Ossimitz, G. 2002. Stock-Flow-Thinking and reading stock-flowrelated graphs: An empirical investigation in dynamic thinking abilities Proceedings of the 20th International Conference of the System Dynamics Society, Polermo, Italy.

Pala, Ö., \& Vennix, A. M. 2005. Effects of system dynamics education on systems thinking inventory task performance. System Dynamics Review, 21(2): 147-172.

Pfeffer, J., \& Fong, C. T. 2002. The end of business schools? Less success than meets the eye. Academy of Management Learning and Education, 1: 78-95.

Porter, L. W., \& McKibbin, L. E. 1988. Management education and development: Drift or thrust into the 21st century: New-York, NY: McGrow Hill.

Repenning, N. P. 2003. Selling system dynamics to (other) social scientists. System Dynamics Review, 19(4): 303-327.

Richmond, B. 2000. The thinking in systems thinking: Seven essential skills. Waltham, MA: Pegasus Communications Inc.

Schlesinger, L. A., \& Whitestone, D. 1983. People Express (A) Case. Harvard Business School Publishing. 
Senge, P. M. 1990. The fifth discipline: The art \& practice of the learning organization, 27-54, New York, NY: Doubleday/ Currency.

Steiner, T. L., \& Wells, R. M. J. 2000. Integration of the business curriculum: The case of finance and marketing in a MBA program. Financial Practice and Education, Fall/Winter: $148-159$.

Sterman, J. D. 2000. Business dynamics: Systems thinking and modeling for a complex world, 3-39. Irwin-McGraw-Hill.
Umpleby, S. A., \& Dent, E. B. 1999. The origins and purposes of several traditionons in systems theory and cybernetics. $C_{Y}$ bernetics and Systems: An International Journal, 30: 79-103

Von Bertalanfy, L., 1969. General systems theory: Foundations, developments, applications. New York: George Braziller, Inc.

Wickens, C. D. 1992. Engineering psychology and human performance, 2nd ed., 211-257. New York: HarperCollins.

J. Brian Atwater is an associate professor of production/operations management in the Jon M. Huntsman School of Business, Utah State University. He teaches graduate courses in systems thinking and operations management. He works as an examiner for the Shingo Prize for Excellence in Manufacturing and he has provided training and other professional consulting services for a wide variety of businesses including Apple Computers Inc., Carrier Transicold Inc., Schuller/Manville Corporation, and 3M Corporation. He has published articles in a variety of journals including the Production \& Operations Management Journal, International Journal of Production Research, International Journal of Operations \& Production Management, Productions Inventory Management Journal, Cost Management Journal, and Industrial Management Journal.

Vijay R. Kannan is Vernon \& Maree Buehler Endowed Professor and professor of operations management in the Jon M. Huntsman School of Business, Utah State University. Dr. Kannan earned his $\mathrm{PhD}$ in operations management from Michigan State University. He has published extensively in the areas of cellular manufacturing, quality management, and supply chain management. His articles appear in journals including Decision Sciences, International Journal of Production Research, International Journal of Operations and Production Management, and Quality Management Journal. Kannan's current research examines the impact of buyersupplier relationships in supply chains, and manufacturing strategy in developing economies.

Alan A. Stephens is the department head of the Business Administration Department and an associate professor of finance in the Jon M. Huntsman School of Business, Utah State University. Dr. Stephens' primary areas of expertise are in corporate finance and investments. He is currently participating in research concerning systemic thinking, systems thinking in finance, as well as other financial markets research. He has been retained in a broad variety of consulting engagements with private firms, governmental entities, and individuals. These engagements have dealt with many different types of financial and economic analyses, engineering and land-use studies, actuarial analysis and advice, and matters in litigation. 
Copyright of Academy of Management Learning \& Education is the property of Academy of Management and its content may not be copied or emailed to multiple sites or posted to a listserv without the copyright holder's express written permission. However, users may print, download, or email articles for individual use. 